\title{
c.⿲丿丨. \\ Oxidative Depolymerization of Lignin Using Supported Niobium Catalysts
}

\author{
Lalitendu Das ${ }^{1}$, Praveen Kolar ${ }^{1, *}$, Ratna Sharma-Shivappa ${ }^{1}$, John J. Classen ${ }^{1}$ \\ and Jason A. Osborne ${ }^{2}$ \\ 1 Biological and Agricultural Engineering, Campus Box 7625, North Carolina State University, Raleigh, \\ NC 27695-7625, USA; ldas@ncsu.edu (L.D.); rsharm2@ncsu.edu (R.S.-S.); classen@ncsu.edu (J.J.C.) \\ 2 Department of Statistics, Campus Box 8203, North Carolina State University, Raleigh, NC 27695-8203, USA; \\ Jason.osborne@ncsu.edu \\ * Correspondence: pkolar@ncsu.edu; Tel.: +1-919-513-9797
}

Received: 18 October 2017; Accepted: 20 November 2017; Published: 29 November 2017

\begin{abstract}
Valorization of lignin into aromatics has driven researchers for decades. In this research, niobium was deposited on oyster shells (OSNC) and carbon rods (CRNC) and tested as a catalyst for depolymerization of lignin. Catalysts $(2 \%, 5 \%$, and $8 \%$ loading) were synthesized via wet impregnation. Batch experiments were performed at $95^{\circ} \mathrm{C}$, using $8 \mathrm{~g}$ of lignin, and $1 \mathrm{~g}$ of catalyst. Our research indicates that niobium supported catalysts are effective in partial oxidation of lignin. Maximum vanillin concentration for OSNC was found to be $86.25 \mathrm{mg} \mathrm{L}^{-1}(0.1 \mathrm{wt} \%)$ at $5 \%$ niobium whereas, as for CRNC, maximum vanillin concentration was found to be $139.40 \mathrm{mg} \mathrm{L}^{-1}(0.17 \mathrm{wt} \%)$ at $2 \%$ niobium loading. Addition of hydrogen peroxide into the batch reactor decreased the concentration of vanillin production.
\end{abstract}

Keywords: lignin; catalytic oxidation; niobium; carbon rod; oyster shell

\section{Introduction}

Use of lignocellulosic feedstocks as precursors for the production of chemicals and value-added products have generated a significant interest lately [1-5]. Depolymerization of lignin into value-added aromatics is one of the most important routes in biomass deconstruction [6]. Lignin is an excellent precursor for the synthesis of aromatic chemicals [3]. However, due to its complex nature, it is challenging to effectively depolymerize lignin into low molecular weight compounds [7]. Hence, most of the industrial lignin produced in the world is combusted for heat production [8,9].

Lignin is biosynthesized via oxidative coupling of monomers, i.e., sinapyl alcohol, coniferyl alcohol, and $p$-coumaryl alcohol, into a branched polymer [10]. It may be noted that the structure of lignin and its monomers depend on the plant type. The complexity of lignin structure arises from cross-coupling of monomers with other phenolic units. Lignin inter-unit linkages, mainly $\beta-\mathrm{O}-4, \beta-\beta$, $\beta-5,5-5$, and $5-\mathrm{O}-4$ are the $\mathrm{C}-\mathrm{O}$ and $\mathrm{C}-\mathrm{C}$ bonds. Their abundance may vary depending on the plant type, with $\beta-\mathrm{O}-4$ being the most common linkage. However, despite the recalcitrant nature of lignin, its structural and chemical properties can be exploited to convert lignin into useful chemicals.

Many researchers studied lignin model compounds to understand its cleavage mechanism and parameters affecting its degradation, subsequently extending the application to whole lignin [11]. Several degradation methods including thermal, chemical, and biochemical conversion of lignin have been proposed to produce an array of chemicals. However, oxidative pathways can yield some of the fine chemicals such as simple aldehydes (vanillin, syringaldehyde, $p$-hydroxybenzaldehyde) or acids, such as vanillic acid and syringic acid $[10,12,13]$.

Several reports are available in the literature focused on lignin oxidation using hydrogen peroxide, oxygen, and other chemical oxidants in the presence or absence of a catalyst. Crestini et al. [14] 
employed $\mathrm{CH}_{3} \mathrm{ReO}_{3}$ as a catalyst and $\mathrm{H}_{2} \mathrm{O}_{2}$ as an oxidant at room temperature for oxidation of lignin model compounds, sugar cane lignin, and red spruce kraft lignin. Their study indicated that hydrolytic sugarcane lignin, red spruce kraft lignin, and hardwood organosolvent lignin produced aliphatic $\mathrm{OH}$, syringol $\mathrm{OH}$, guaiacyl $\mathrm{OH}$, $p$-hydroxy phenyl $\mathrm{OH}$, and $\mathrm{COOH}$ with yields ranging from $0.29 \%$ to $1.51 \%$. Similarly, Herrmann et al. [15] also used $\mathrm{CH}_{3} \mathrm{ReO}_{3}$ catalyst in the presence of $\mathrm{H}_{2} \mathrm{O}_{2}$ for oxidation of trans-ferulic acid and isoeugenol at $60^{\circ} \mathrm{C}$ for $10 \mathrm{~h}$ to produce vanillin. Sales and co-workers [16] investigated the effect of $\mathrm{Pd} / \mathrm{Al}_{2} \mathrm{O}_{3}(2.85 \mathrm{wt} \%)$ as a catalyst for oxidation of lignin derived from sugarcane bagasse in presence of $\mathrm{O}_{2}$ in slurry and continuous fluidized bed reactors. Experimental results indicated that $0.56 \mathrm{~g}$ of vanillin and $0.50 \mathrm{~g}$ of syringaldehyde were produced from $60 \mathrm{~g} \mathrm{~L}^{-1}$ of lignin at $120^{\circ} \mathrm{C}$ and 5.00 bar pressure (after $2 \mathrm{~h}$ of reaction) from the batch reactor and $6.5 \mathrm{~g}$ vanillin and $11.4 \mathrm{~g}$ of syringaldehyde were obtained (from $30 \mathrm{~g} \mathrm{~L}^{-1}$ of lignin) from fluidized bed reactors from under identical operating conditions. Additionally, catalytic oxidation of lignin into chemicals in various solvents and metal oxides including $\mathrm{Ni}, \mathrm{Co}, \mathrm{V}, \mathrm{Cu}$, and $\mathrm{Fe}$ as catalysts in the presence of various oxidizing agents have been successfully tested [2].

Oxidation of lignin into desired chemicals requires a selective catalyst that would minimize secondary oxidation reactions. One such selective catalyst is niobium. Application of niobium as an effective and selective catalyst for several oxidation reactions has been well documented [17-19]. Rooke et al. [18] used hierarchically-porous $\mathrm{Nb}_{2} \mathrm{O}_{5}$ and $\mathrm{Ta}_{2} \mathrm{O}_{5}$ materials as supports to deposit $\mathrm{Pd}$ for the oxidation of toluene. Similarly, niobium oxide was tested as a catalyst for aldol condensation of acetone to produce mesytilene and acetic acid [19]. Further, niobium compounds are also known to exhibit the characteristics of support and promoter. When supported on other oxides, niobium compounds significantly increase the catalytic activity [20-22]. In addition, niobium oxide also acts as a strong Lewis acid and can stabilize oxidative cation species [23-25]. As a result, supported niobium catalysts have been employed in hydrogenation, methylisobutyl ketone synthesis, metathesis, and hydrotreating reactions [20]. However, there is no scientific data on the activity of supported niobium catalysts for lignin oxidative degradation. Considering the selectivity of niobium compounds, it is hypothesized that niobium-supported catalysts can depolymerize lignin. In this research, oyster shell and carbon rods, both inexpensive precursors, were selected as catalyst supports because of their ability to support impregnation of metals on their surfaces and easy availability. In the United States alone, about 35 million pounds of oysters are produced [26], of which approximately 30 million tons of oyster shell waste [27] are generated that could be valorized. In addition, oyster shells are rich in calcium and possess high structural integrity needed to serve as catalyst supports. As a result, oyster shells were previously investigated as support for impregnation of KI for use in transesterification [28]. Additionally, [29] employed oyster shell powder as catalyst support for dispersing $\mathrm{Cu}$ catalyst for production of synthesis of 1,2,3-triazoles. Similarly, supported-carbon catalysts have been used by several researchers for a variety of applications, including oxidation reactions $[30,31]$. Thus, niobium impregnated on an oyster shell and carbon rods were synthesized as catalysts for use in lignin oxidation.

\section{Materials and Methods}

\subsection{Materials}

Oyster (eastern oyster, Crassostrea virginica) shells were procured from a local restaurant in Raleigh, NC. Solid niobium oxalate $\left(\mathrm{C}_{10} \mathrm{H}_{5} \mathrm{NbO}_{20}\right)$, alkaline lignin (Kraft), were purchased from Alfa Aesar, Inc. (Tewksbury, MA, USA) and Tokyo Chemical Industry Inc. (Tokyo, Japan). Methylene chloride $(99.99 \%)$, carbon rods, and hydrogen peroxide $(50 \% v / v)$ were procured from Fisher Scientific, Inc. (Hampton, NH, USA) Standards for calibration (4-hydroxy-3-methoxybenzaldehyde (99\%) and 4-hydroxy-3-methoxyacetophenone (98\%)) were obtained from Acros Organics USA (Morris, NJ, USA). 


\subsection{Catalyst Synthesis}

Oyster shells were washed thoroughly with water and calcined at $400{ }^{\circ} \mathrm{C}$ for $2 \mathrm{~h}$. After calcination, shells were broken to the size of 1-2 mm using a hand hammer. Broken shells were then treated with $2 \%, 5 \%$, and $8 \%$ niobium oxalate in an aqueous solution of oxalic acid (11 wt $\%)$, Subsequently, the niobium-impregnated shells were recalcined at $1000{ }^{\circ} \mathrm{C}$ for $4 \mathrm{~h}$ and were named as oyster shell-supported niobium catalyst (OSNC) (Figure 1A). Similarly, carbon rod-supported niobium catalysts (CRNC) were prepared by impregnating $2 \%, 5 \%$, and $8 \%$ niobium oxalate (as described above) and calcining the niobium-impregnated shells at $200{ }^{\circ} \mathrm{C}$ for $5 \mathrm{~h}$ (Figure 1B).
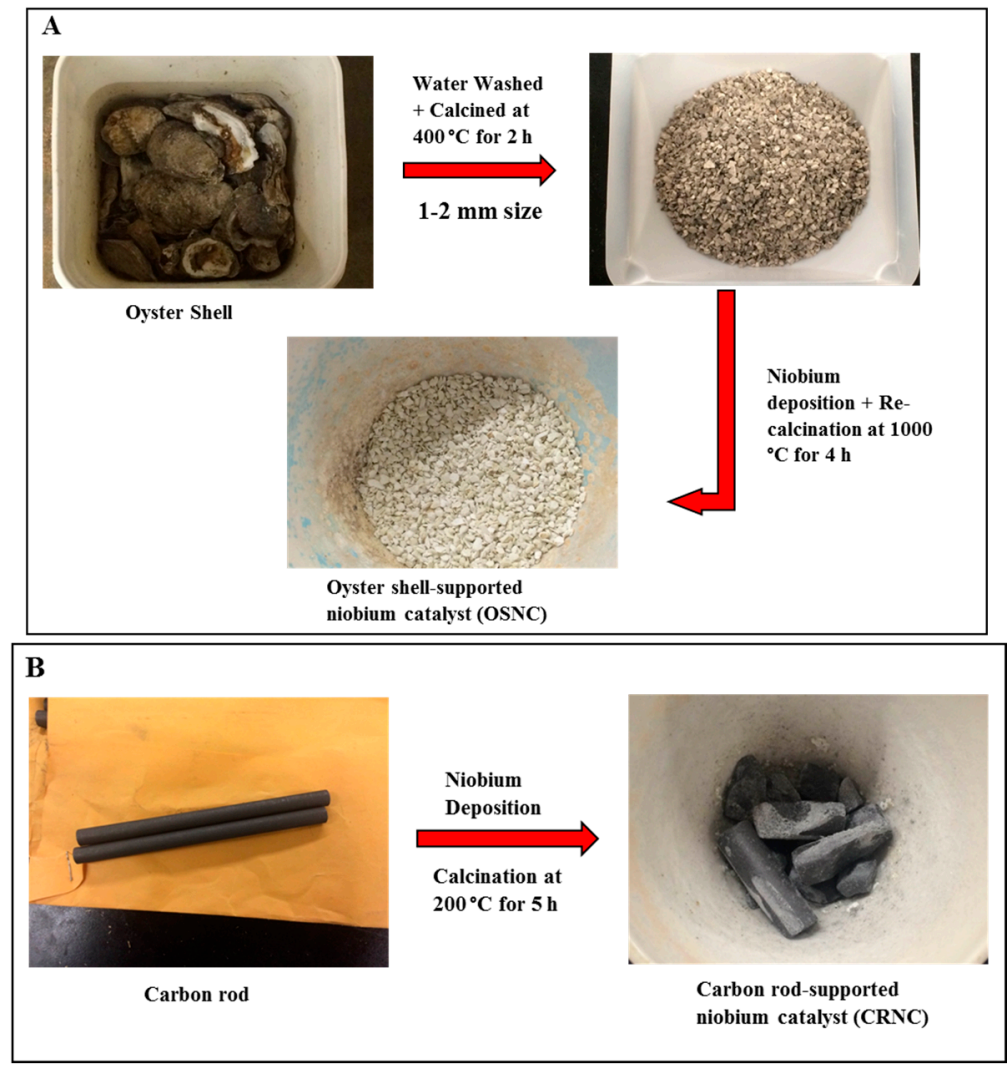

Figure 1. Synthesis of (A) oyster shell-supported niobium catalyst (OSNC) and (B) carbon rod-supported niobium catalyst (CRNC).

\subsection{Catalyst Testing and Analytical Methods}

Catalytic oxidation experiments were carried out in batch reactors. Briefly, $100 \mathrm{~mL}$ of aqueous solutions (8 g $100 \mathrm{~mL}^{-1}$ of lignin, $1 \mathrm{~g} 100 \mathrm{~mL}^{-1}$ of catalyst) were added to $500-\mathrm{mL}$ three-neck glass reactors. The contents of the reactor were mixed at $150 \mathrm{rpm}$ and heated to a temperature of $95^{\circ} \mathrm{C}$ on a thermocouple equipped process-controlled hot plate (IsoTemp, Fisher Scientific, Waltham, MA, USA), capable of maintaining the temperatures within $\pm 5^{\circ} \mathrm{C}$. Control experiments were performed with oyster shells and carbon rods without catalyst deposition. To determine the effect of the oxidant, experiments were performed by adding $0.5 \mathrm{~mL} 100 \mathrm{~mL}^{-1}$ of $\mathrm{H}_{2} \mathrm{O}_{2}$ to the batch experiments. For OSNC, experiments were conducted for $60 \mathrm{~min}$ whereas, for CRNC, experiments were extended for $180 \mathrm{~min}$. Samples $(1.5 \mathrm{~mL})$ from the reactor were collected periodically, at 10 min-intervals and 20 min-intervals for OSNC and CRNC, respectively. Subsequently, liquid-liquid extraction was performed using methylene chloride $(2.5 \mathrm{~mL})$ in order to extract phenolic compounds and the extracted samples were stored at $4{ }^{\circ} \mathrm{C}$ for further analysis. The liquid extracted samples were analyzed via an Agilent gas chromatograph (7890A)-MS (Agilent Technologies, 5975C, Santa Clara, CA, USA) coupled with a DB-5 
MS UI column $(30 \mathrm{~m} \times 0.25 \mathrm{~mm} \times 0.25 \mu \mathrm{m})$ with UHP helium as the carrier gas $\left(1.2 \mathrm{~mL} \mathrm{~min}{ }^{-1}\right)$. For sample analysis and quantification, the oven temperature was manipulated as follows: $100{ }^{\circ} \mathrm{C}$ for $1 \mathrm{~min}$, followed by a temperature increase of $20^{\circ} \mathrm{C} \mathrm{min}-1$ until the temperature reached $200{ }^{\circ} \mathrm{C}$, and $15^{\circ} \mathrm{C} \mathrm{min}^{-1}$ until the temperature reached $270{ }^{\circ} \mathrm{C}$ and held for $1 \mathrm{~min}$. The injector and detector were set to $300{ }^{\circ} \mathrm{C}$ and the split ratio was set to 150:1. Calibration curves were prepared using pure vanillin and acetovanillone obtained from Acros Organics USA. All experiments were performed in duplicate.

\section{Results and Discussion}

\subsection{Catalyst Testing and Oxidation Products}

Product analysis and quantification were performed using a gas chromatogram attached to a mass spectroscope. Identified products were vanillin, acetovanillone and homovanillic acid (Figure 2). Concentrations and conversion of vanillin for OSNC at $2 \%, 5 \%$, and $8 \%$ loading were $40.08 \mathrm{mg} \mathrm{L}^{-1}$ $(0.05 \mathrm{wt} \%), 86.25 \mathrm{mg} \mathrm{L}^{-1}\left(0.1 \mathrm{wt}^{\mathrm{o}}\right)$ and $39.01 \mathrm{mg} \mathrm{L}^{-1}(0.05 \mathrm{wt} \%)$, respectively. However, for the same catalyst loading, when hydrogen peroxide $(0.5 \mathrm{~mL})$ was introduced to the system, the concentrations were $37.63 \mathrm{mg} \mathrm{L}^{-1}\left(0.04 \mathrm{wt}^{2}\right)$, $34.53 \mathrm{mg} \mathrm{L}^{-1}(0.04 \mathrm{wt} \%)$, and $36.77 \mathrm{mg} \mathrm{L}^{-1}(0.04 \mathrm{wt} \%)$, respectively. Similarly, for CRNC, concentrations of vanillin at $2 \%, 5 \%$, and $8 \%$ loading were $139.40 \mathrm{mg} \mathrm{L}^{-1}$ (0.17 $\mathrm{wt} \%), 95.97 \mathrm{mg} \mathrm{L}^{-1}(0.1 \mathrm{wt} \%)$, and $75.16 \mathrm{mg} \mathrm{L}^{-1}(0.09 \mathrm{wt} \%)$, respectively, and $88.18 \mathrm{mg} \mathrm{L}^{-1}$ $(0.1 \mathrm{wt} \%), 86.78 \mathrm{mg} \mathrm{L}^{-1}(0.1 \mathrm{wt} \%)$, and $84.75 \mathrm{mg} \mathrm{L}^{-1}(0.1 \mathrm{wt} \%)$, respectively, with the addition of hydrogen peroxide.

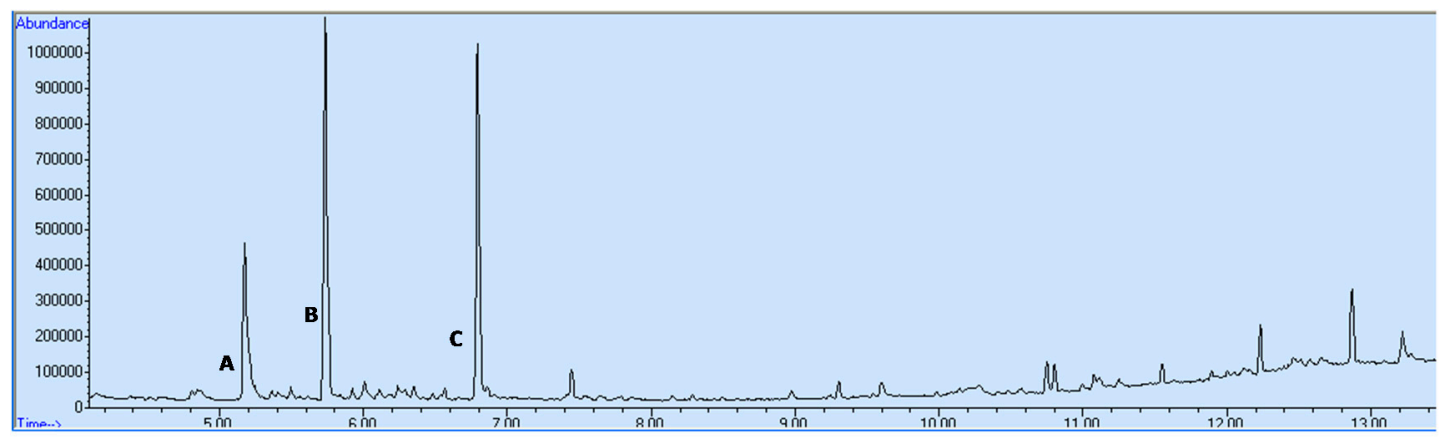

Figure 2. Representative chromatogram (Abundance vs Time) collected from lignin oxidation experiments. (A) 4-hydroxy-3-methoxybenzaldehyde, (B) 1-(4-hydroxy-3-methoxyphenyl)-ethanone, and (C) 4-hydroxy-3-methoxy benzenacetic acid.

\subsection{Oyster Shell-Supported Niobium Catalyst}

Oyster shell was employed as a support to deposit niobium oxalate to synthesize OSNC. Figure 3A, $B$ illustrates the effect of catalyst loading on the concentration of vanillin and acetovanillone respectively. Catalyst with $5 \%$ loading provided the highest concentration of $86.25 \mathrm{mg} \mathrm{L}^{-1}(0.1 \mathrm{wt} \%)$ at $10 \mathrm{~min}$. However, further prolongation of the reaction decreased the concentration of products whereas after $10 \mathrm{~min}$ of reaction time at $2 \%$ and $8 \%$ of niobium loading showed little or no change in concentrations of vanillin and acetovanillone. The highest concentration of $9.50 \mathrm{mg} \mathrm{L}^{-1}(0.01 \mathrm{wt} \%)$ acetovanillone was achieved at $8 \%$ loading and for a reaction time of $10 \mathrm{~min}$. At $2 \%$ loading, vanillin concentration was found to be lower than vanillin concentration obtained at $5 \%$ loading, probably because of an inadequate amount of niobium species required for the reaction. On the other hand, at $8 \%$ loading, the concentration of vanillin was lower than that of at $2 \%$ loading, perhaps because excess niobium particles may have blocked the pores on the catalyst surface, thereby lowering the product formation. It may also be possible that strong metal-oxygen bond strength may have decreased the activity of the catalyst. The oxidation trend with niobium oxide supported oyster shell catalysts are similar to 
those obtained by other researchers. For example, Villar et al. [32] investigated oxidation (with oxygen) of hardwood kraft lignin under alkaline conditions using $\mathrm{CuSO}_{4}, \mathrm{CoCl}_{2}$, and $\mathrm{Co}$ (II) salen catalysts and reported that the yields of aldehydes did not increase when copper (II) and cobalt (II) loading increased perhaps due to subsequent oxidation of the reaction products.
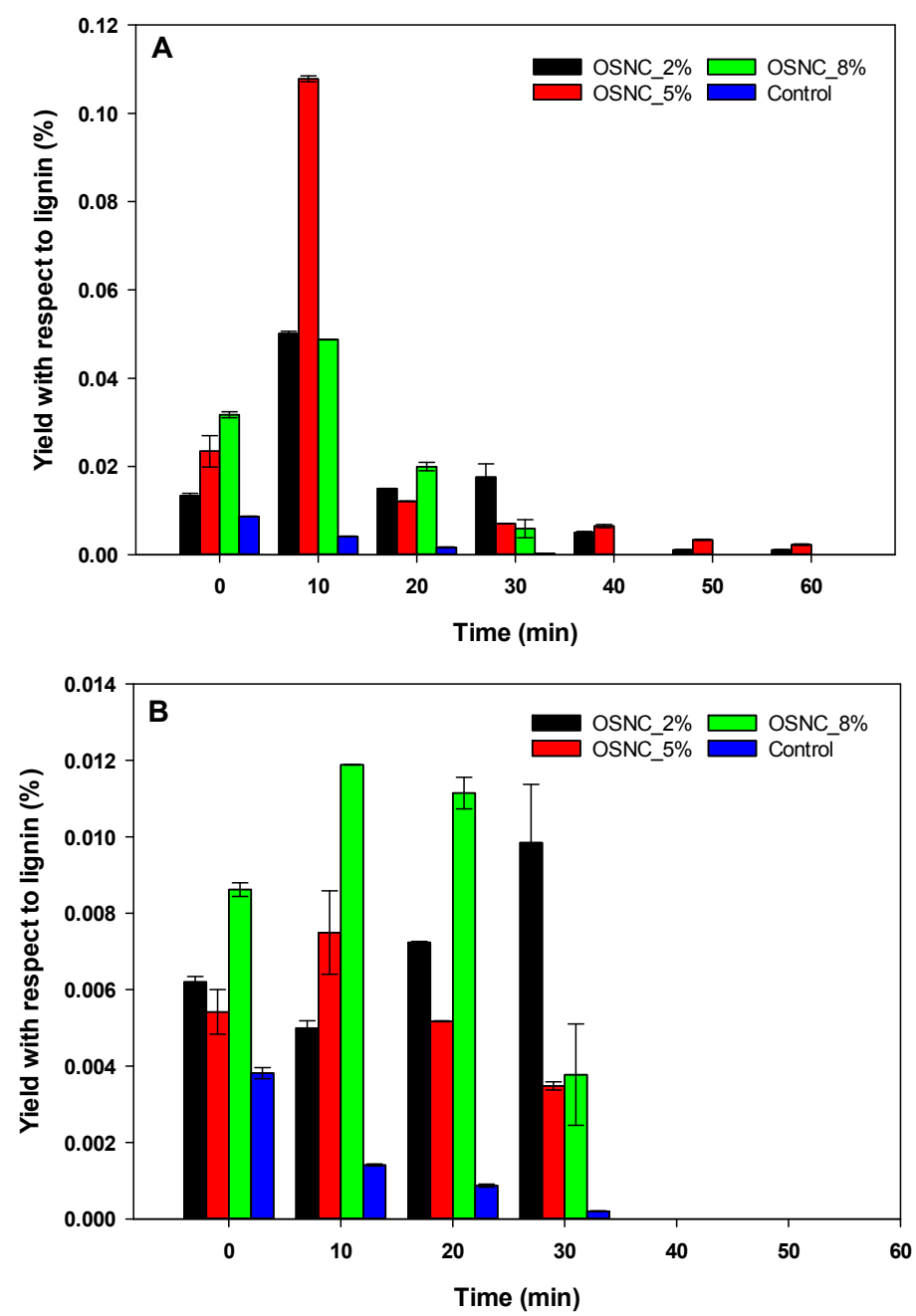

Figure 3. The yield of vanillin (A) and acetovanillone (B) using OSNC when $8 \mathrm{~g} 100 \mathrm{~mL}^{-1}$ of lignin was depolymerized with $1 \mathrm{~g} 100 \mathrm{~mL}^{-1}$ catalyst at $95^{\circ} \mathrm{C}$.

The yields obtained in our research were lower than those reported by other researchers. For example, De Gregorio et al. [33] employed vanadium-based polyoxometalate as a catalyst in the presence of ionic liquid (IL) 1-butylimidazolium hydrogensulfate. The reported product yields for vanillin, syringaldehyde, and guaiacol were $0.055 \%$ with respect to lignin. Similarly, Rodrigues and co-workers [34] investigated the oxidative conversion of four softwood and three hardwood lignins in an alkaline medium in presence of molecular oxygen. Vanillin yield from the softwoods were $3.1 \%$ to $4.4 \%$ with respect to lignin, while hardwood lignin yielded $1.2 \%$ of vanillin and $2.5 \%$ of syringaldehyde. The yields obtained in our research were lower than those obtained by other researchers perhaps due to the absence of alkaline medium and a suitable solvent, as employed in the aforementioned studies. It may be noted that we did not use any $\mathrm{NaOH}$ or ionic liquids to dissolve lignin in our research. Addition of either of these reagents may enhance product yields when used with niobium catalysts. Moreover, from Figure 3A, it is evident that around $60 \mathrm{~min}$, vanillin concentration was essentially approaching zero, which may be due to oxidation of vanillin to other products which were not detected by GC-MS. Based on the findings from our study, product yields can be improved, via either immediate 
harvesting of vanillin to prevent from further degradation or quenching the reaction early to minimize the oxidation reaction. Additionally, it may be possible to fine-tune the catalyst synthesis to disperse an optimum concentration of niobium on the support surface to minimize secondary oxidation reactions.

To investigate the effect of $\mathrm{H}_{2} \mathrm{O}_{2}$ on the activity of niobium catalyst, $0.5 \mathrm{~mL}$ of $\mathrm{H}_{2} \mathrm{O}_{2}$ was added to the system. Figure $4 \mathrm{~A}, \mathrm{~B}$ illustrates the effect of $\mathrm{H}_{2} \mathrm{O}_{2}$ on vanillin and acetovanillone production. The results indicate that the reaction was nearly instantaneous. Although an increase in the concentration of products was observed during the initial phase of the reaction, the products seem to become over-oxidized, perhaps by excess oxidant in the system. Similar results were reported in our previous study where $\mathrm{H}_{2} \mathrm{O}$ in presence of niobium oxalate catalyst caused over-oxidation of products [35] as was also reported by Xiang and Lee [36], who noted a decrease in overall product concentration. It was postulated that aldehydes were subjected to rapid degradation by hydrogen peroxide and it is suggested that use of a less reactive oxidant, such as molecular oxygen might improve the product yield. Additionally, the decrease in product concentration in our study may have been due to the reaction of hydroxyl ion produced from the decomposition of $\mathrm{CaO}$ in the aqueous phase with $\mathrm{H}_{2} \mathrm{O}_{2}$ to form perhydroxyl anion. These reactive anions could have facilitated the deconstruction of $\alpha$ and $\beta$-aryl ether bonds in lignin into aldehydes, but at the same time produced aldehydes that are vulnerable to further oxidation [37].
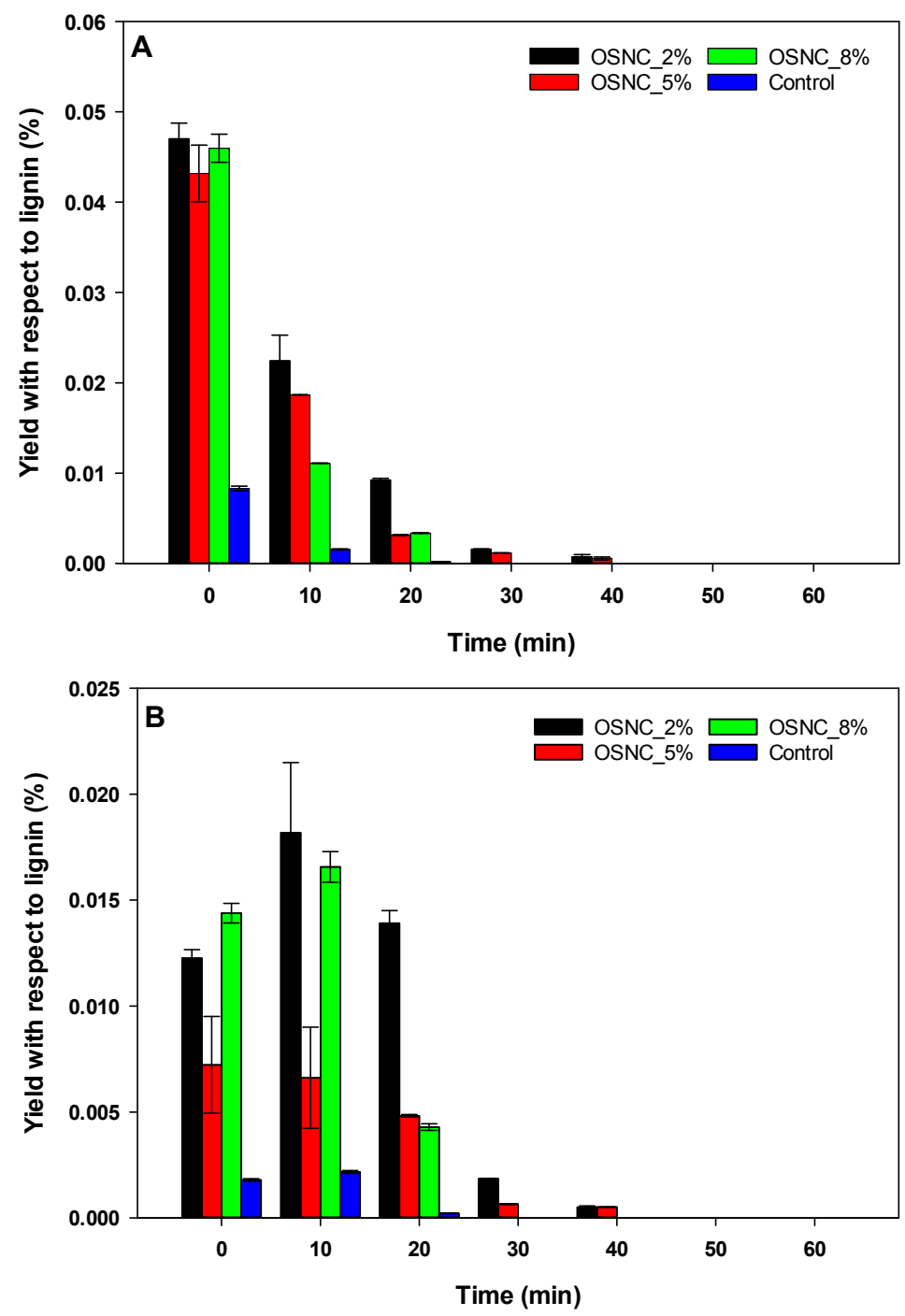

Figure 4. The yield of vanillin (A) and acetovanillone (B) using OSNC when $8 \mathrm{~g} 100 \mathrm{~mL}^{-1}$ of lignin was depolymerized with $1 \mathrm{~g} 100 \mathrm{~mL}^{-1}$ catalyst and $0.5 \mathrm{~mL}$ of $\mathrm{H}_{2} \mathrm{O}_{2}$ at $95{ }^{\circ} \mathrm{C}$. 


\subsection{Carbon Rod Supported Niobium Catalyst}

When the carbon rod-supported niobium catalyst (CSNC) was tested for depolymerization of lignin, the concentration of vanillin increased significantly. A maximum vanillin concentration of $139.40 \mathrm{mg} \mathrm{L}^{-1}(0.17 \mathrm{wt} \%)$ was obtained at $2 \%$ loading (120 min reaction time). Concentration and conversion of vanillin decreased from $95.97 \mathrm{mg} \mathrm{L}^{-1}(0.1 \mathrm{wt} \%)$, to $75.16 \mathrm{mg} \mathrm{L}^{-1}(0.09 \mathrm{wt} \%)$ as loading was increased from $5 \%$ to $8 \%$. Figure $5 \mathrm{~A}, \mathrm{~B}$ depicts vanillin and acetovanillone obtained from catalysts with different loadings of niobium oxalate. A maximum acetovanillone concentration of $39.88 \mathrm{mg} \mathrm{L}^{-1}(0.05 \mathrm{wt} \%)$ was observed at $2 \%$ loading after $100 \mathrm{~min}$. Interestingly, concentration for both vanillin and acetovanillone increased again after $140 \mathrm{~min}$, perhaps due to repolymerization of the products. In a recent study, Shao et al. [38], explored the selective production of arenes from organosolv lignin via direct hydrodeoxygenation over a porous $\mathrm{Ru} / \mathrm{Nb}_{2} \mathrm{O}_{5}$ catalyst. The conversion of lignin to C7-C9 hydrocarbons resulted in a total mass yield of $35.5 \mathrm{wt} \%$ with the arene selectivity of $71 \mathrm{wt} \%$. The yield of vanillin from lignin with and without the presence of a catalyst varies widely in the literature. For instance, Villar and coworkers [32] reported $4 \%$ yield while Sales and co-workers [39] observed 1.7\%. Similarly, the maximum yield for pine lignin reported by Mathias and co-workers was about $10 \%$ [40]. Taken together, carbon rod-supported catalyst successfully degraded lignin to produce 4-hydroxy-3-methoxybenzaldehyde, 1-(4-hydroxy-3-methoxyphenyl)-ethanone, and 4-hydroxy-3-methoxy benzenacetic acid.
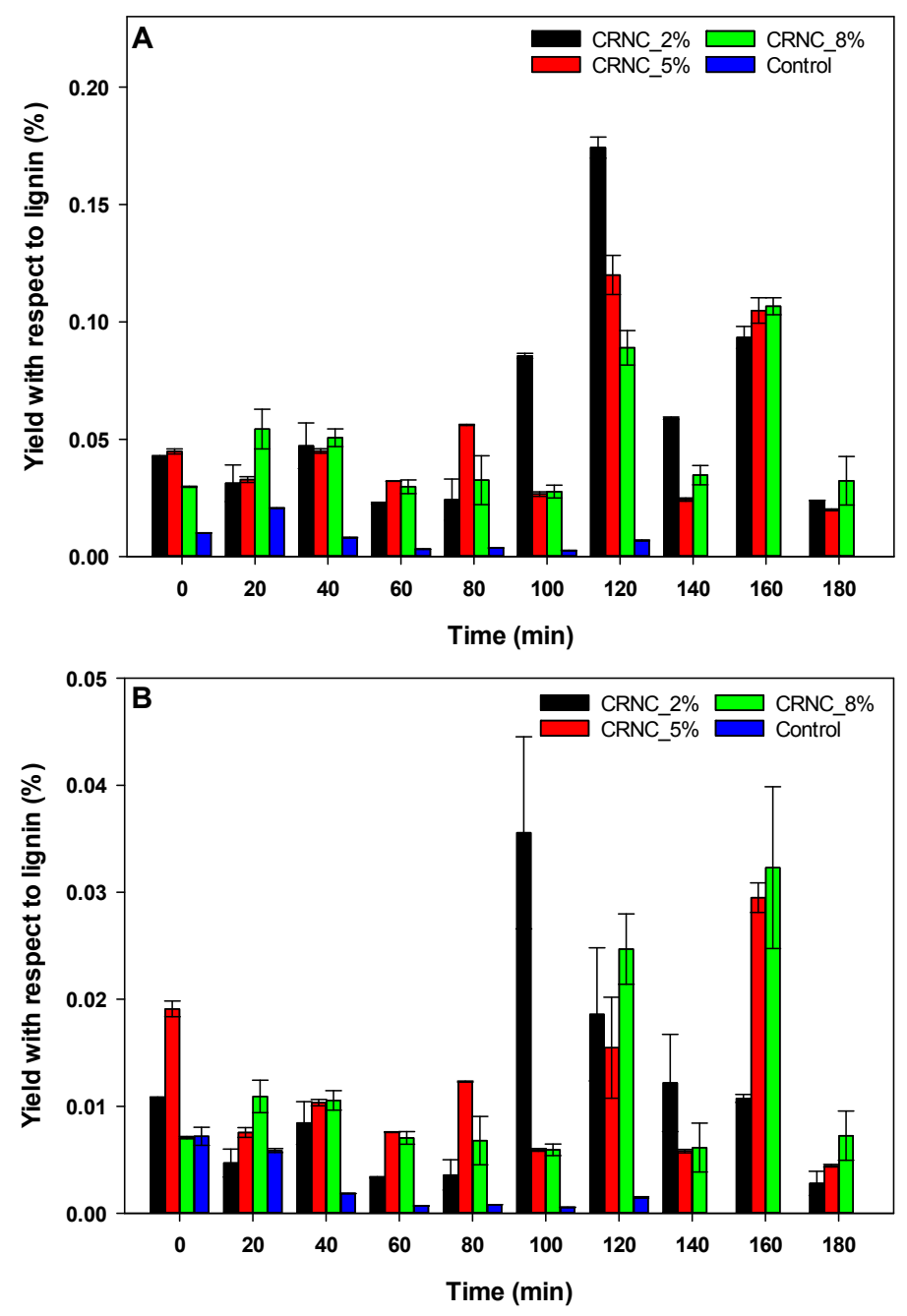

Figure 5. The yield of vanillin (A) and acetovanillone (B) using CRNC when $8 \mathrm{~g} 100 \mathrm{~mL}^{-1}$ of lignin was depolymerized with $1 \mathrm{~g} 100 \mathrm{~mL}^{-1}$ catalyst at $95^{\circ} \mathrm{C}$. 
Experiments were also conducted to test $\mathrm{H}_{2} \mathrm{O}_{2}$ as an oxidizing agent. In a separate batch experiment, $0.5 \mathrm{~mL} \mathrm{H}_{2} \mathrm{O}_{2}$ was added to the system to investigate the lignin depolymerization. Figure $6 \mathrm{~A}, \mathrm{~B}$ illustrates the effect of $\mathrm{H}_{2} \mathrm{O}_{2}$ on production of vanillin and acetovanillone using CSNC. Again, there was an increase in the product concentration when the reaction started. However, as the reaction progressed, $\mathrm{H}_{2} \mathrm{O}_{2}$ seems to have no significant influence on product concentration. It is theorized that the lattice oxygen present in the catalyst was able to facilitate oxidation of lignin, but the addition of $\mathrm{H}_{2} \mathrm{O}_{2}$ seems to provide additional reactive oxygen species that may have further initiated subsequent oxidation reactions. In a similar study, Dier et al. [41], investigated the electrochemical degradation of alkali and organosolv lignin ionic liquids 1-ethyl-3-methylimidazolium trifluoromethanesulfonate and triethylammonium methanesulfonate. They reported a significant reduction (13-51\%) in total compounds when $\mathrm{H}_{2} \mathrm{O}_{2}$ was introduced in the system, most likely attributed to over-oxidation [41]. Overall, observations from this study suggest additional studies to increase the yield of products via increased alkalinity and optimized niobium loading on the supports.
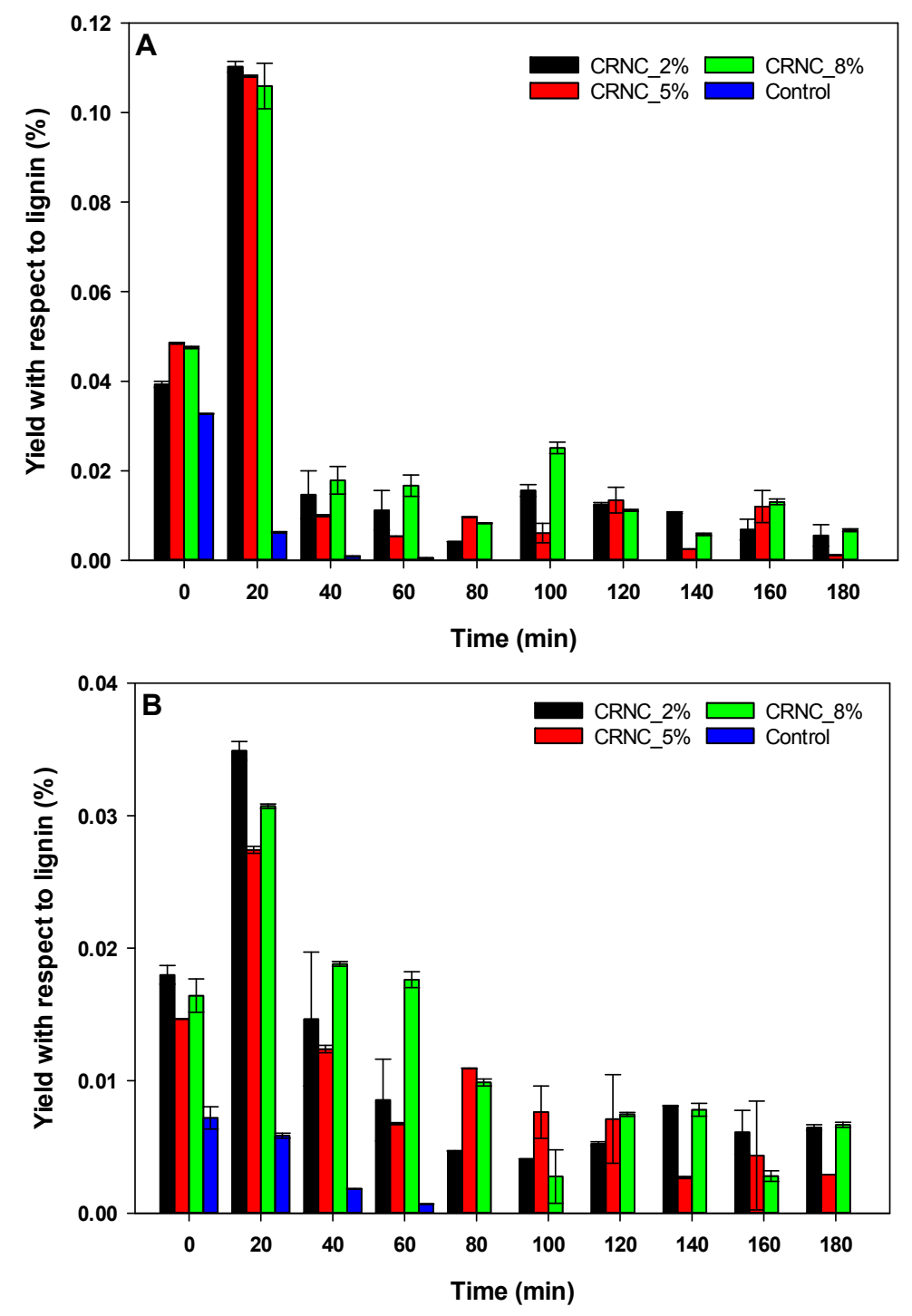

Figure 6. The yield of vanillin (A) and acetovanillone (B) using CRNC when $8 \mathrm{~g} 100 \mathrm{~mL}^{-1}$ of lignin was depolymerized with $1 \mathrm{~g} 100 \mathrm{~mL}^{-1}$ catalyst and $0.5 \mathrm{~mL}$ of $\mathrm{H}_{2} \mathrm{O}_{2}$ at $95^{\circ} \mathrm{C}$.

The product yields obtained from both catalysts with different niobium loadings are summarized in Table 1. Overall, it appeared that yields of vanillin and acetovanillone obtained from CRNC were 
higher than the yields from OSNC suggesting that carbon rod supports received higher amounts of niobium when compared to oyster shell. In addition to a higher mass loading of niobium on the carbon support, the synergistic interaction between carbon and niobium may have resulted in increased active sites that could also have contributed to increased product yields when compared to OSNC. Synergistic effects of catalyst support on selective oxidation have been previously documented. In one of their reports on selective oxidation of benzyl alcohol to benzaldehyde, Wu et al. [42] observed that graphene support was able to enhance adsorption of oxygen and benzyl alcohol on the catalyst surface. Similarly, Wang et al. [43] demonstrated the collaborative effects of copper support and gold catalyst in the selective oxidation of benzyl alcohol. In our research, carbon rod support may have promoted the oxidation reaction via enhanced adsorption of lignin and perhaps enhanced the lattice oxygen transfer between the support and catalyst, as suggested by $\mathrm{Xu}$ et al. [44].

Table 1. Maximum yield with respect to lignin (\%) obtained from OSNC and CRNC at different niobium loadings.

\begin{tabular}{rcccccc}
\hline & \multicolumn{5}{c}{ Niobium Loading } \\
\cline { 2 - 7 } Sample & \multicolumn{2}{c}{$\mathbf{2 \%}$ Niobium Loading } & $\mathbf{5 \%}$ Niobium Loading & \multicolumn{2}{c}{$\mathbf{8 \%}$ Niobium Loading } \\
\cline { 2 - 7 } & $\begin{array}{c}\text { Vanillin } \\
\text { Yield (\%) }\end{array}$ & $\begin{array}{c}\text { Acetovanillone } \\
\text { Yield (\%) }\end{array}$ & $\begin{array}{c}\text { Vanillin } \\
\text { Yield (\%) }\end{array}$ & $\begin{array}{c}\text { Acetovanillone } \\
\text { Yield (\%) }\end{array}$ & $\begin{array}{c}\text { Vanillin } \\
\text { Yield (\%) }\end{array}$ & $\begin{array}{c}\text { Acetovanillone } \\
\text { Yield (\%) }\end{array}$ \\
\hline OSNC & 0.05 & 0.01 & 0.1 & 0.01 & 0.05 & 0.01 \\
CRNC & 0.17 & 0.03 & 0.1 & 0.02 & 0.09 & 0.03 \\
\hline
\end{tabular}

\section{Future Directions}

As evident in our data, the yields of products are low. The lower yields obtained in this study may be attributed to repolymerization of lignin and/or over-oxidation of lignin degradation products which were not detected through GC-MS. However, it may be possible to enhance the product yields by manipulating experimental conditions. It may be noted that in our research, the $\mathrm{pH}$ of the system was around 8 as we did not adjust the $\mathrm{pH}$ of the reactants. Several researchers, including [45-47], have noted the role of $\mathrm{pH}$ in lignin oxidation into chemicals. From an oxidation perspective, an increase in $\mathrm{pH}$ will promote oxidation of lignin [48]. Under alkaline conditions, especially the presence of sodium hydroxide will facilitate solubilization of lignin for subsequent depolymerization reactions [49]. In one of their reports, Kindisigo et al. [50] observed that increasing pH from 5 to 12 enhanced lignin depolymerization by about $40 \%$. Further, Pandey and Kim [2,51], described a free-radical oxidation mechanism that was originally proposed by Tarabanko, in which alkaline medium promotes the formation of phenoxyl radical that eventually converts depolymerized lignin into vanillin. Mathias and Rodrigues [40] reported that lignin was dissolved by hydroxyl ions to form polyphenolate ions that further reacted with the oxidant via a free radical reaction to yield vanillin/syringaldehyde. Based on the available literature, it appears that higher $\mathrm{pH}>10$ is suitable for formation of aldehydes because lower $\mathrm{pH}$ accelerated subsequent oxidation of vanillin [52-54]. daSilva et al. [55] observed a significant decrease in vanillin yields from lignin derived from Pinus sp and Indulin AT when $\mathrm{pH}$ of the reaction system was lowered from 14 to 10. Furthermore, as pointed out by Behling et al. [56], $\mathrm{pH}$ control will also promote the formation of reactive oxygen species capable of enhancing the selectivity of end products and minimizing repolymerization. Hence, further studies should be carried out to improve the product yield by optimizing the $\mathrm{pH}$ of the reaction. In addition, advanced catalyst preparation techniques combined with simultaneous recovery of products will contribute to increased product yields. For example, in oxidation reactions, the desired intermediate (product) molecules are highly susceptible to subsequent degradation. This is especially true if the product molecules have immediate access to catalytic sites. As product molecules adsorb on the catalyst, they tend to react with oxidant/lattice oxygen to form $\mathrm{CO}_{2}$ and $\mathrm{H}_{2} \mathrm{O}$. To minimize these reactions, newer catalysts may be synthesized by increasing the distance between the catalyst sites. One way to accomplish this to 
use site isolation technique as proposed by Grasselli [57], who suggested that selective separation of lattice oxygen atoms on the surface significantly enhances selectivity and increases product yields. Similarly, product recovery via a continuous system will limit the chances of secondary oxidation of aldehydes and acids [39,52]. Therefore, future studies on preparation of selective catalysts coupled with a continuous reaction system are suggested. Furthermore, optimizing catalyst preparation methods will also play an important role in enhancing product yields. For example, investigating the effects of niobium concentration and calcination temperature on product yields will provide valuable information on correct precursor concentration and calcination temperature to maximize the product yields. Taken together, based on previous literature and insights gained from our results, some of the approaches to improve product yield could be (i) adjusting the $\mathrm{pH}$ of the reaction system to increase hydroxide ion concentration; (ii) selection and synthesis of advanced catalysts; and (iii) the recovery of products via a continuous system or biphasic system.

\section{Conclusions}

Alkaline lignin was oxidized to low molecular products using niobium supported on the oyster shell and carbon rod catalysts. As hypothesized, both OSNC and CRNC depolymerized lignin into smaller molecular weight aldehydes and acids. Production of vanillin from OSNC catalyst for $2 \%, 5 \%$, and $8 \%$ niobium loading were $0.05,0.1$, and $0.05 \mathrm{wt} \%$, respectively, relative to the lignin dry weight. In presence of CRNC catalyst, vanillin conversion was $0.17 \mathrm{wt} \%$ ( $2 \%$ loading), $0.1 \mathrm{wt} \%$ ( $5 \%$ loading), and $0.09 \mathrm{wt} \%$ ( $8 \%$ loading). In presence of hydrogen peroxide, the product concentrations decreased due to subsequent oxidation, suggesting that lignin oxidation reaction needs to be further optimized. Product yield could be improved by fine-tuning dispersion of niobium, increasing the alkalinity of the system, and by implementing continuous recovery of products to minimize over oxidation.

Acknowledgments: We thank the National Science Foundation/Industry-University Cooperative Research Centers Program for funding this research.

Author Contributions: Lalitendu Das and Praveen Kolar conceptualized the work; Jason A. Osborne designed the experiments and analyzed data; Lalitendu Das conducted the experiments; and all the authors contributed to writing, editing of the manuscript. All authors have approved the manuscript and agreed with submission to ChemEngineering.

Conflicts of Interest: The authors declare no conflict of interest.

\section{References}

1. Long, J.; Zhang, Q.; Wang, T.; Zhang, X.; Xu, Y.; Ma, L. An efficient and economical process for lignin depolymerization in biomass-derived solvent tetrahydrofuran. Bioresour. Technol. 2014, 154, 10-17. [CrossRef] [PubMed]

2. Zakzeski, J.; Bruijnincx, P.C.; Jongerius, A.L.; Weckhuysen, B.M. The catalytic valorization of lignin for the production of renewable chemicals. Chem. Rev. 2010, 110, 3552-3599. [CrossRef] [PubMed]

3. Cherubini, F.; Strømman, A.H. Chemicals from lignocellulosic biomass: Opportunities, perspectives, and potential of biorefinery systems. Biofuels Bioprod. Biorefin. 2011, 5, 548-561. [CrossRef]

4. Sanyoto, B.; Dwiatmoko, A.A.; Choi, J.-W.; Ha, J.-M.; Suh, D.J.; Kim, C.S.; Lim, J.-C. Catalytic depolymerization of alkali lignin using supported Pt nanoparticle catalysts. J. Nanosci. Nanotechnol. 2016, 16, 4570-4575. [CrossRef] [PubMed]

5. Chaudhary, R.; Dhepe, P.L. Solid base catalyzed depolymerization of lignin into low molecular weight products. Green Chem. 2017, 19, 778-788. [CrossRef]

6. Nanayakkara, S.; Patti, A.F.; Saito, K. Lignin depolymerization with phenol via redistribution mechanism in ionic liquids. ACS Sustain. Chem. Eng. 2014, 2, 2159-2164. [CrossRef]

7. Ragauskas, A.J.; Beckham, G.T.; Biddy, M.J.; Chandra, R.; Chen, F.; Davis, M.F.; Davison, B.H.; Dixon, R.A.; Gilna, P.; Keller, M. Lignin valorization: Improving lignin processing in the biorefinery. Science 2014, 344, 1246843. [CrossRef] [PubMed] 
8. Tomani, P.; Axegård, P.; Berglin, N.; Lovell, A.; Nordgren, D. Integration of lignin removal into a kraft pulp mill and use of lignin as a biofuel. Cellul. Chem. Technol. 2011, 45, 533.

9. Wu, W.; Dutta, T.; Varman, A.M.; Eudes, A.; Manalansan, B.; Loqué, D.; Singh, S. Lignin valorization: Two hybrid biochemical routes for the conversion of polymeric lignin into value-added chemicals. Sci. Rep. 2017, 7, 8420. [CrossRef] [PubMed]

10. Azarpira, A.; Ralph, J.; Lu, F. Catalytic alkaline oxidation of lignin and its model compounds: A pathway to aromatic biochemicals. Bioenergy Res. 2014, 7, 78-86. [CrossRef]

11. Xu, C.; Arancon, R.A.D.; Labidi, J.; Luque, R. Lignin depolymerisation strategies: Towards valuable chemicals and fuels. Chem. Soc. Rev. 2014, 43, 7485-7500. [CrossRef] [PubMed]

12. Crestini, C.; Crucianelli, M.; Orlandi, M.; Saladino, R. Oxidative strategies in lignin chemistry: A new environmental friendly approach for the functionalisation of lignin and lignocellulosic fibers. Catal. Today 2010, 156, 8-22. [CrossRef]

13. Ma, R.; Guo, M.; Zhang, X. Recent advances in oxidative valorization of lignin. Catal. Today 2017. [CrossRef]

14. Crestini, C.; Caponi, M.C.; Argyropoulos, D.S.; Saladino, R. Immobilized methyltrioxo rhenium (MTO)/ $\mathrm{H}_{2} \mathrm{O}_{2}$ systems for the oxidation of lignin and lignin model compounds. Bioorg. Med. Chem. 2006, 14, 5292-5302. [CrossRef] [PubMed]

15. Hermans, I.; Spier, E.S.; Neuenschwander, U.; Turrà, N.; Baiker, A. Selective oxidation catalysis: Opportunities and challenges. Top. Catal. 2009, 52, 1162-1174. [CrossRef]

16. Sales, F.G.; Maranhão, L.C.; Lima Filho, N.M.; Abreu, C.A. Kinetic evaluation and modeling of lignin catalytic wet oxidation to selective production of aromatic aldehydes. Ind. Eng. Chem. Res. 2006, 45, 6627-6631. [CrossRef]

17. Wachs, I.E.; Briand, L.E.; Jehng, J.-M.; Burcham, L.; Gao, X. Molecular structure and reactivity of the Group V metal oxides. Catal. Today 2000, 57, 323-330. [CrossRef]

18. Rooke, J.; Barakat, T.; Siffert, S.; Su, B.-L. Total catalytic oxidation of toluene using pd impregnated on hierarchically porous $\mathrm{Nb}_{2} \mathrm{O}_{5}$ and $\mathrm{Ta}_{2} \mathrm{O}_{5}$ supports. Catal. Today 2012, 192, 183-188. [CrossRef]

19. Paulis, M.; Martın, M.; Soria, D.; Diaz, A.; Odriozola, J.; Montes, M. Preparation and characterization of niobium oxide for the catalytic aldol condensation of acetone. Appl. Catal. A Gen. 1999, 180, 411-420. [CrossRef]

20. Tanabe, K. Catalytic application of niobium compounds. Catal. Today 2003, 78, 65-77. [CrossRef]

21. Ziolek, M. Niobium-containing catalysts-The state of the art. Catal. Today 2003, 78, 47-64. [CrossRef]

22. Jehng, J.-M.; Wachs, I. Niobium oxalate: A new precursor for the preparation of supported niobium oxide catalysts. Am. Chem. Soc. Div. Pet. Chem. 1989, 34, 546-550.

23. Nakajima, K.; Baba, Y.; Noma, R.; Kitano, M.; Kondo, J.N.; Hayashi, S.; Hara, M. $\mathrm{Nb}_{2} \mathrm{O}_{5} \cdot \mathrm{nH}_{2} \mathrm{O}$ as a heterogeneous catalyst with water-tolerant lewis acid sites. J. Am. Chem. Soc. 2011, 133, 4224-4227. [CrossRef] [PubMed]

24. Wu, X.N.; Tang, S.Y.; Zhao, H.T.; Weiske, T.; Schlangen, M.; Schwarz, H. Thermal ethane activation by bare $\left[\mathrm{V}_{2} \mathrm{O}_{5}\right]^{+}$and $\left[\mathrm{Nb}_{2} \mathrm{O}_{5}\right]^{+}$cluster cations: On the origin of their different reactivities. Chem. Eur. J. 2014, 20, 6672-6677. [CrossRef] [PubMed]

25. Carniato, F.; Bisio, C.; Psaro, R.; Marchese, L.; Guidotti, M. Niobium (V) saponite clay for the catalytic oxidative abatement of chemical warfare agents. Angew. Chem. Int. Ed. Engl. 2014, 15, 10095-10098. [CrossRef] [PubMed]

26. Oysters in the U.S. Available online: http://www.nmfs.noaa.gov/aquaculture/homepage_stories/05_ national_oyster_day_2015.html (accessed on 11th November, 2017).

27. Lorio, W.J.; Malone, S. The Cultivation of American Oysters (Crassostrea virginica); Southern Regional Aquaculture Center: Stoneville, MS, USA, 1994.

28. Jairam, S.; Kolar, P.; Sharma-Shivappa, R.; Osborne, J.A.; Davis, J.P. Ki-impregnated oyster shell as a solid catalyst for soybean oil transesterification. Bioresour. Technol. 2012, 104, 329-335. [CrossRef] [PubMed]

29. Xiong, X.; Cai, L.; Jiang, Y.; Han, Q. Eco-efficient, green, and scalable synthesis of 1,2,3-triazoles catalyzed by $\mathrm{Cu}(\mathrm{I})$ catalyst on waste oyster shell powders. ACS Sustain. Chem. Eng. 2014, 2, 765-771. [CrossRef]

30. Auer, E.; Freund, A.; Pietsch, J.; Tacke, T. Carbons as supports for industrial precious metal catalysts. Appl. Catal. A Gen. 1998, 173, 259-271. [CrossRef]

31. Yang, Y.; Chiang, K.; Burke, N. Porous carbon-supported catalysts for energy and environmental applications: A short review. Catal. Today 2011, 178, 197-205. [CrossRef] 
32. Villar, J.; Caperos, A.; Garcia-Ochoa, F. Oxidation of hardwood kraft-lignin to phenolic derivatives with oxygen as oxidant. Wood Sci. Technol. 2001, 35, 245-255. [CrossRef]

33. De Gregorio, G.F.; Prado, R.; Vriamont, C.; Erdocia, X.; Labidi, J.; Hallett, J.P.; Welton, T. Oxidative depolymerization of lignin using a novel polyoxometalate-protic ionic liquid system. ACS Sustain. Chem. Eng. 2016, 4, 6031-6036. [CrossRef]

34. Rodrigues Pinto, P.C.; Borges da Silva, E.A.; Rodrigues, A.E. Insights into oxidative conversion of lignin to high-added-value phenolic aldehydes. Ind. Eng. Chem. Res. 2010, 50, 741-748. [CrossRef]

35. Das, L.; Kolar, P.; Osborne, J.; Sharma-Shivappa, R.; Classen, J. Selective oxidation of lignin into aromatic aldehydes using niobium oxalate. Am. Soc. Agric. Biol. Eng. 2016, 59, 727-735. [CrossRef]

36. Xiang, Q.; Lee, Y. Oxidative cracking of precipitated hardwood lignin by hydrogen peroxide. Appl. Biochem. Biotechnol. 2000, 84, 153-162. [CrossRef]

37. Kadla, J.F.; Chang, H. The Reactions of Peroxides with Lignin and Lignin Model Compounds; ACS Publications: Columbia, DC, USA, 2001.

38. Shao, Y.; Xia, Q.; Dong, L.; Liu, X.; Han, X.; Parker, S.F.; Cheng, Y.; Daemen, L.L.; Ramirez-Cuesta, A.J.; Yang, S. Selective production of arenes via direct lignin upgrading over a niobium-based catalyst. Nat. Commun. 2017, 8. [CrossRef] [PubMed]

39. Sales, F.G.; Maranhão, L.C.; Lima Filho, N.M.; Abreu, C.A. Experimental evaluation and continuous catalytic process for fine aldehyde production from lignin. Chem. Eng. Sci. 2007, 62, 5386-5391. [CrossRef]

40. Mathias, A.; Rodrigues, A. Production of vanillin by oxidation of pine kraft lignins with oxygen. Holzforsch. Int. J. Biol. Chem. Phys. Technol. Wood 1995, 49, 273-278. [CrossRef]

41. Dier, T.K.; Rauber, D.; Durneata, D.; Hempelmann, R.; Volmer, D.A. Sustainable electrochemical depolymerization of lignin in reusable ionic liquids. Sci. Rep. 2017, 7. [CrossRef] [PubMed]

42. Wu, G.; Wang, X.; Guan, N.; Li, L. Palladium on graphene as efficient catalyst for solvent-free aerobic oxidation of aromatic alcohols: Role of graphene support. Appl. Catal. B Environ. 2013, 136, 177-185. [CrossRef]

43. Wang, H.; Fan, W.; He, Y.; Wang, J.; Kondo, J.N.; Tatsumi, T. Selective oxidation of alcohols to aldehydes/ketones over copper oxide-supported gold catalysts. J. Catal. 2013, 299, 10-19. [CrossRef]

44. Xu, J.; Shang, J.-K.; Wang, Y.; Chen, Y.; Li, Y.-X. Synthesis of mesoporous cemno materials and catalytic application for selective oxidation of benzyl alcohol by molecular oxygen. Catal. Lett. 2017, 147, 328-334. [CrossRef]

45. Fargues, C.; Mathias, Á.; Rodrigues, A. Kinetics of vanillin production from kraft lignin oxidation. Ind. Eng. Chem. Res. 1996, 35, 28-36. [CrossRef]

46. Araújo, J.D.; Grande, C.A.; Rodrigues, A.E. Vanillin production from lignin oxidation in a batch reactor. Chem. Eng. Res. Des. 2010, 88, 1024-1032. [CrossRef]

47. Cheng, C.; Wang, J.; Shen, D.; Xue, J.; Guan, S.; Gu, S.; Luo, K.H. Catalytic oxidation of lignin in solvent systems for production of renewable chemicals: A review. Polymers 2017, 9, 240. [CrossRef]

48. Kang, S.; Li, X.; Fan, J.; Chang, J. Hydrothermal conversion of lignin: A review. Renew.Sustain. Energy Rev. 2013, 27, 546-558. [CrossRef]

49. Demesa, A.G.; Laari, A.; Turunen, I.; Sillanpää, M. Alkaline partial wet oxidation of lignin for the production of carboxylic acids. Chem. Eng. Technol. 2015, 38, 2270-2278. [CrossRef]

50. Kindsigo, M.; Hautaniemi, M.; Kallas, J. Wet oxidation of recalcitrant lignin water solutions: Experimental and reaction kinetics. Environ. Chem. Lett. 2009, 7, 155. [CrossRef]

51. Pandey, M.P.; Kim, C.S. Lignin depolymerization and conversion: A review of thermochemical methods. Chem. Eng. Technol. 2011, 34, 29-41. [CrossRef]

52. Araújo, J.D.; Grande, C.A.; Rodrigues, A.E. Structured packed bubble column reactor for continuous production of vanillin from kraft lignin oxidation. Catal. Today 2009, 147, S330-S335. [CrossRef]

53. Fache, M.; Boutevin, B.; Caillol, S. Vanillin production from lignin and its use as a renewable chemical. ACS Sustain. Chem. Eng. 2015, 4, 35-46. [CrossRef]

54. Maziero, P.; de Oliveira Neto, M.; Machado, D.; Batista, T.; Cavalheiro, C.C.S.; Neumann, M.G.; Craievich, A.F.; de Moraes Rocha, G.J.; Polikarpov, I.; Goncalves, A.R. Structural features of lignin obtained at different alkaline oxidation conditions from sugarcane bagasse. Ind. Crops Prod. 2012, 35, 61-69. [CrossRef] 
55. Da Silva, E.B.; Zabkova, M.; Araújo, J.; Cateto, C.; Barreiro, M.; Belgacem, M.; Rodrigues, A. An integrated process to produce vanillin and lignin-based polyurethanes from kraft lignin. Chem. Eng. Res. Des. 2009, 87, 1276-1292. [CrossRef]

56. Behling, R.; Valange, S.; Chatel, G. Heterogeneous catalytic oxidation for lignin valorization into valuable chemicals: What results? What limitations? What trends? Green Chem. 2016, 18, 1839-1854. [CrossRef]

57. Grasselli, R.K. Genesis of site isolation and phase cooperation in selective oxidation catalysis. Top. Catal. 2001, 15, 93-101. [CrossRef]

(C) 2017 by the authors. Licensee MDPI, Basel, Switzerland. This article is an open access article distributed under the terms and conditions of the Creative Commons Attribution (CC BY) license (http:/ / creativecommons.org/licenses/by/4.0/). 